\title{
Extraction and Refining of Rare and Rare-earth Oxides from Complex Iron-bearing Concentrates for Applications in Energy Devices
}

\author{
Anmiesh Jha ${ }^{1 *}$, Vitalis Chipawke ${ }^{1}$, Stephen Ghambi ${ }^{1,2}$, Sergio S. Segado ${ }^{1,3}$, Abhishek Lahiri ${ }^{1,4}$ \\ ${ }^{1}$ School of Chemical and Process Engineering, Faculty of Engineering and Physical Sciences, University of Leeds, Leeds \\ LS2 9JT, UK \\ ${ }^{2}$ Department of Mining Engineering, University of Malawi - The Polytechnic, P/Bag 303, Chichiri, Blantyre 3, Malawi. \\ ${ }^{3}$ Chemical and Process Engineering Group, Department of Industrial and Environmental Engineering, Universidad \\ Politecnica de Cartagena, Mucia, Spain. \\ ${ }^{4}$ Technical University, Adolf-Roemer Strasse 2A, Clausthal D-38678 Germany
}

The rare-earth lanthanide $\left(\mathrm{Ln}^{3+}\right)$ oxides often co-exist with the ilmenite and zircon sands, and are considered undesirable impurities in the titanium dioxide and zirconium oxide products, because the $\mathrm{Ln}^{3+}$-oxides form colour centres and impart colour in $\mathrm{TiO}_{2}$ and $\mathrm{ZrO}_{2}$ matrices. The separation of $\mathrm{Ln}^{3+}$-ions during processing of titaniferous minerals is energy demanding, as a result the purification costs are high. The rare oxides of niobium and tantalum, however, are found with tin-bearing coulombite and tantalite minerals, where rare-earth and titanium dioxide may also co-exist.

Also, as the richer resources of titaniferous minerals and zirconia are diminishing in the world, the leaner deposits with higher concentrations of rare-earth oxides are becoming more important for developing methodologies, that would not only yield the primary oxides $\left(\mathrm{TiO}_{2}\right.$ and $\left.\mathrm{ZrO}_{2}\right)$, but also secondary metal oxides such as rare-earth oxides for further processing. Coulombite and tantalite concentrates are processed using hydrofluoric acid, causing huge damage to environment, equipment, and human beings.

In this keynote lecture, the main focus will be to demonstrate the applications of alkali roasting of complex minerals at elevated temperatures in oxidising and reducing conditions, e.g. above $700^{\circ} \mathrm{C}$ for primary extraction of valuable metal oxides, which can be then further refined for making products. The roles of crystal chemistry and alkali complexation processes are explained in the context of energetics. The differences in the physical chemistry of the separation of rareand rare-earth oxides from complex tantalite, coulombite and monazite minerals are also explained, by investigating the morphologies and compositions of the phases formed.

The importance of hydrometallurgical steps for refining the products is also explained for the rare-earth and coulombite/tantalite family of minerals. From the mixture of RE oxides in colloid forms, the separation of $\mathrm{Nd}_{2} \mathrm{O}_{3}$ and $\mathrm{Pr}_{2} \mathrm{O}_{3}$ were carried out for magnetic materials manufacturing, however, the $\mathrm{CeO}_{2}$ and $\mathrm{La}_{2} \mathrm{O}_{3}$ were separated for catalyst and alloy manufacturing for catalytic convertors and fuel cell applications.

Further leaching of alkali titanate is carried out with oxalic $(0.3 \mathrm{M})$ and ascorbic $(0.01 \mathrm{M})$ acid solution which removes the remaining $\mathrm{Fe}^{2+}$ ions into the leachate and allows precipitation of high-purity synthetic rutile containing more than $95 \%$ $\mathrm{TiO}_{2}$. The impact of such strategic materials is critical in defining the renewable landscape of a country. 